\title{
Source of Information on Health should be from Respondent and Community not from Health Worker
}

\section{Atheer K Ibadi*}

Department of Pharmacy, Kufa Institute, Al Furat Al-Awsat Technical University, Iraq

*Corresponding author: Atheer Kadhim Ibadi, Assistant professor, PhD Community Health- Communicable Diseases, Head of pharmacy Department, Kufa Institute, Al Furat Al-Awsat Technical University, Iraq, Tel: 00964781514192; Email: atheerkadhimibadi@yahoo.com

\section{Letter to Editor}

Most important point in the validity of any research is the information about the problem should be taken from sample of the study (respondent) or study population not from health workers. There are many of academic and research centers classified the research data into two types of sources are active and passive resources. According to this basis, the researches that be established basis on passive resource will be incompletely valid and can't depend on it in scientific research ether cant generalize these results because these researches have built according to resources effected by more than one type of bias.

Human scientific researchers are conducted to search in the causes of occurrence of specific problem or to figure out that problem. Next, it's affecting significantly in morbidity and mortality of diseases. Right now, noncommunicable diseases like cancers, environmental, nutritional and water pollution diseases are considered very crucial problem, this was determining by Middle
East- Europe Forum since 2018. According to this, many organizations around the word have established specific programs to reduce the morbidity and mortality of diseases even 2020. Most of those evaluations were established according to real and dependable resources to determine these problems.

The validity of this topic extends to the validity of researchers in searching for correct health information when looking for a particular problem. In addition, the researcher is based on that information to build the scientific theory of scientific research they want to do. Strictly, the red line should be there, and the researcher should be standup on it, and much effort should be made to identify data collection resources related to the study problem.

Finally, validity is the basis in scientific research to collect the data for any problem. 